\title{
Teacher Metacognition within the Professional Learning Community
}

\author{
Michelle P. Prytula ${ }^{1}$ \\ ${ }^{1}$ University of Saskatchewan, Canada \\ Correspondence: Michelle P. Prytula, Department of Educational Administration, College of Education, \\ University of Saskatchewan, 28 Campus Drive Saskatoon, SK S7N 0X1, Canada. Tel: 306-966-6880. Facsimile: \\ (306) 966-7020. E-mail: michelle.prytula@usask.ca
}

\author{
Received: April 17, 2012 Accepted: April 29, 2012 Online Published: June 25, 2012 \\ doi:10.5539/ies.v5n4p112 URL: http://dx.doi.org/10.5539/ies.v5n4p112
}

\begin{abstract}
A study of teacher metacognition within the context of the professional learning community (PLC) was conducted to understand how teachers describe their metacognition, what they describe as the catalysts to their metacognition, and how metacognition influences their work. Although the PLC was used as a context for the study, the findings include that the PLC was an environment in which teacher metacognition could be nurtured, and that the PLC leaders' recognition of their own metacognition impacted the type of work that they led in the PLC, thus potentially impacting the learning of others.
\end{abstract}

Keywords: teacher metacognition, professional learning communities, teacher learning, professional development

\section{Introduction}

In educational contexts, the term metacognition is frequently used to explain the process by which students learn to understand their thinking, with the idea that if they can regulate their thinking, they will be better learners (Perfect \& Schwartz, 2002; Robson, 2006). The word metacognition, although possessing multiple definitions and multiple interpretations, has a stronghold in educational vernacular, so much so that educational policy-makers expect that educating students to think metacognitively will help students to become more self-regulative learners (Harskamp \& Henry, 2009). More recently, however, the term has become incresingly important in the realms of teacher professional development, with the understanding that if teachers are able to teach students to be metacognitive or to think metacognitively, then teachers must think metacognitively themselves, as well as be aware of when metacognition is taking place. "The ability to self-regulate learning is essential for teachers' professional growth during their entire career as well as for their ability to promote these processes among students" (Kramarski \& Michalsky, 2009, p. 161). The reality is, however, that one cannot teach what one doesn't know; thus teacher metacognition is an important area reqiring exploration.

Employing a phenomenological approach, a constructive study of teacher metacognition within the context of the professional learning community (PLC) was conducted to gain a better understanding of teacher metacognition. Specifically, a study was conducted to understand how teachers describe their metacognition, what they describe as the catalysts to their metacognition, and how metacognition influences their work. For this study, the PLC was used as a bounded context within which to study teacher metacognition. The reason for this is that the PLC involves an environment of collaboration and inquiry; one with an "active, reflective, collaborative, learning-oriented, and growth-promoting approach toward teaching and learning” (Mitchell \& Sackney, 2000, p. 9). In these communities with regular interactions, it was assumed that deeper thinking and learning were likely to occur.

The findings from this study suggest that the PLC was an environment in which teacher metacognition could be nurtured, and that the PLC leaders' recognition of their own metacognition impacted the type of work that they led in the PLC, thus potentially impacting the learning of others.

\section{Metacognition}

Traditionally defined, metacognition is thinking about thinking or the monitoring and regulation of thinking (Flavell, 1979). Elaborated, "metacognition refers, among other things, to the active monitoring and consequent regulation and orchestration of these processes in relation to the cognitive objects or data on which they bear, usually in service of some concrete goal or objective" (Flavell, 1976, p. 232). Since its appearance in cognitive 
psychology, its definition has been blurred somewhat, as researchers have expanded the term to include different aspects of metacognition, including self-regulation (declarative, procedural, and conditional) (Schraw \& Moshman, 1995), self-regulated learning, motivation, cognition, and meta and non-meta uses of the term, to name a few (Schunk, 2008; Zohar \& Ben David, 2009). There is also a well-described distinction between metacognitive knowledge (knowing about what you know) and metacognitive processes (knowing how to regulate what you know) (Flavell, 1979; Schraw \& Moshman, 1995). Although the term metacognition is inherently broad, its multiple uses can be confusing, thus clarity is required when defining the use of metacognition in research (Schunk, 2008). Metacognition, as used in this study, refers to knowing how to reflect on thought, how to analyze that thought, and how to put thought and analysis to use in the future (Downing, Kwong, Chan, Lam, \& Downing, 2009). Key in this description is that the learner not only knows about his or her own thought processes and others', but can also regulate and direct problem solving to effect changes in thinking - not only for himself but potentially for others as well (Kluwe, 1987).

There is a growing body of literature that has contributed to a greater understanding of the conditions for metacognition and the usage of metacognition for students (Anderson, 2002; Brown, 1987; Downing, et al., 2009; Kramarski \& Michalsky, 2009; Smith, 2005; Wen, 2004; Zohar \& Ben David, 2009). The basis for this interest is founded in the idea that students ought to be life-long learners, equipped with the skills necessary to solve problems in school and to extrapolate these skills into life through understanding their own thinking, learning, and strategic approaches to problem solving (Georghiades, 2004). In order to do this, teachers must understand metacognition themselves and how they use it throughout their professional work. In practice, however, a gap exists in discovering and understanding the metacognitive thought processes of teachers as they engage in professional dialogues and professional development. Making the assumption that teacher learning precedes student learning, and that "many teachers lack sufficient knowledge about metacognition" (Veenman, Van Hout-Wolters, \& Afflerbach, 2006, p. 10), there is a need to further explore teacher metacognition.

\section{Teacher Environments for Metacognition: The Professional Learning Community}

The idea of educators collaboratively working in groups, using one's own and other's knowledge, beliefs, and experiences to construct understandings comes from social constructivist theory (Driscoll, 2000). Giving rise to new knowledge does not happen in isolation where teaching involves simply the transfer of knowledge (Sickle \& Kubinec, 2003), rather new knowledge has the potential to happen when individuals work at solving problems together. Collaboration through collective problem solving results in the deconstruction and reconstruction of knowledge in environments where members are expected to work together. Schon (1995) identified that when a professional reflects on actions or practices "thereby making (them) explicit and subjecting (them) to critique and testing the strategies, assumptions, or problem-settings implicit in a whole repertoire of situational responses" (p. 6) they are capable of thinking about what it is that one is doing and why, so that one can even imagine new ways of doing things and then implementing these new ways.

PLCs consist of a group of people working together to solve a problem or achieve a common goal and are based on the knowledge that learning takes place through authentic tasks embedded in real life (Lave, 1988; Webster-Wright, 2009). Not only does the learning take place in-situ (on-site) through practical experiences, but that reflection and mediated discussion have a valuable role in the process as well (Lieberman \& Pointer Mace, 2008).

As groups of professionals working collaboratively with and learning from one another, the PLC has the power to create lasting impact and change in an organization. This impact is not simply achieved through the adoption of the structure of the PLC, but rather through a transformation in the knowledge, growth, and practice of and among the members involved (Prytula, Makahonuk, Syrota, \& Pesenti, 2009). This transformation is largely due to the activities that the members undertake, such as the practices of collaboration, strategy building, and shared accountability. In teaching, working collaboratively in a PLC includes setting student learning goals, measuring their attainment, and monitoring and planning for further or sustained improvement (Dufour \& Eaker, 1998). Teachers, when engaged in the work of the PLC, experience a "confrontation of values, assumptions, belief systems, and practices that individuals embrace” (Mitchell \& Sackney, 2000, p. 13). Members question approaches, examine effective strategies, and work at solving problems that exist in their schools. "Collaborative conversations call on team members to make public what has traditionally been private - goals, strategies, materials, pacing, questions, concerns, and results” (DuFour, 2004, p. 10). When teachers are engaged in this collaborative problem solving, deeper thinking, or a degree of metacognition is likely to occur.

Because PLCs are situated in the constructivist realm, and because these PLCs are used as a strategy for solving problems of teaching and learning in schools (Dufour \& Eaker, 1998), it can be assumed that metacognition occurs 
to some degree in the minds of individuals in successful PLCs. Thus, it was appropriate to conduct a study of teacher metacognition within the context of PLCs with the purpose of producing an understanding of teachers' metacognitive experiences as they moved through the PLC experience.

\section{Method}

The purpose of this study was to investigate teacher metacognition within the context of successful PLCs to gain a better understanding of how teachers describe their metacognition, what they describe as the catalysts to their metacognition, and how metacognition influences their work. Because metacognition is difficult to access and describe (Georghiades, 2004), a phenomenological approach was chosen in order to attain rich descriptions of the participants' experiences, and to produce a representation of metacognition within a PLC. According to Moustakas (1994), a phenomenological study requires that data be collected from individuals who have experienced the phenomenon, thus this study required purposive sampling. Analogous to purposive sampling, "criterion based sampling requires that one establish the criteria, bases, or standards necessary for units to be included in the investigation (and) then finds a sample that matches these criteria” (Merriam, 1998, p. 48). The successful PLC was important in that it provided a potential environment in which a teacher may have experienced metacognition.

Through gathering in-depth representations of three individuals, it was not possible to generalize the results, but it was possible to gain a deep understanding of the phenomenon, as well as to compare some of the participants' interpretations. Although a phenomenological study of three participants presents a limitation to the applicability of the study, it was chosen to gather a rich description of the phenomenon as the participants experienced it. The representations were studied individually and the findings were presented as "an essence of the experience of all individuals" (Creswell, 2007, p. 58).

Data were collected from three participants in three separate PLCs using pre-interviews, several semi-structured interviews, and a variety of informal contacts. The researcher operated under the assumption that "it is possible for metacognition to be detected if the learner is able to effectively...describe such understanding" (Georghiades, 2004, p. 374), therefore, the first semi-structured interviews employed stimulated recall through metacognitive interviewing to access the participants' experiences as members of their successful PLCs by having them recount and describe their experiences. Moustakas (1994) recommended that broad questions be used at this stage so that data may be gathered that leads to a description of the experiences. Questions included 'describe your experiences as a member of the PLC', and 'describe a typical PLC meeting'. Data from the first interviews were then reduced and examined for key moments where the participant may have been engaged in deeper thought or experienced critical incidents. The subsequent interviews were designed to access the thinking behind their thinking at the identified critical moments. This focus made it possible for participants to retrospectively describe their thinking as they brought into consciousness the experience of their membership in a PLC. Questions such as 'what were you thinking when' and 'why did you choose to make that decision' were asked at this stage. Data from the subsequent interviews were then horizonalized into similar themes so that collective interpretations and meanings could be reported. Transcripts were coded according to repeated ideas that emerged, and member-checking occurred.

Participant selection for this study involved a school division superintendent and a coordinator for the purposes of identifying potential participants based on their knowledge of the schools and PLCs within the division. For this stage, the definition that PLCs are "a group of educators who work collaboratively with and learn from one another” (Dufour, Dufour, \& Eaker, 2005, p. 9) was used. The assumption was that a PLC that was perceived to be successful likely consisted of more collaborative members than one that was perceived as unsuccessful.

Following PLC identification, principals in each nominated school were asked to identify, within their PLCs, individuals who were a certified classroom teacher with at least five years of experience, and who perceived the PLC as successful. Interestingly, those nominated were also leaders of their PLCs. The three participants chosen for the study were all female, by coincidence, and are described as follows:

Tracey was the leader of a middle years (grades 5-8) PLC. Her PLC came about as a response to the school's Learning Improvement Plan (LIP). The LIP was a division-mandated working document targeting improvement around specific student learning goals. Tracey's PLC was focused on guided reading to improve reading levels in the middle years. Tracey reported that the PLC was successful for the past two years, and she was the leader in both years.

Lisa was also a member of middle years PLC. She emerged as an informal PLC leader because of her knowledge and work ethic. Lisa's PLC was also driven by a school improvement mandate. Lisa's PLC involvement also spanned two years. She did not describe the first year as successful; however, the identified success in the second year, guided by Lisa's experience. The group's success revolved around its goal of implementing a program designed to improve writing skills in the middle years. 
Jacki was a member of a primary years PLC. This PLC was originally driven by the school LIP goals; however, with a change in administration, the PLC's requirements in its second year became much less consistent. Jacki's PLC shifted from a focus on an area of mathematics to a focus on improving reading. Jacki described the first year as highly successful, but did not share the same feelings about its operation in the second year. Jacki emerged as the leader of her PLC because of her years of experience.

Each PLC in this study operated as a group of people working together to solve common problems in teaching and learning. Members of the PLC set common goals, planned together to meet student needs, executed their plans, and measured their success through student learning. To different degrees, the execution of the plans for each PLC entailed collaborative work, strategy sharing, discussions and realignment of strategies, a focus on best practice, and frequent assessment. Each group set benchmarks for their goals and measured student progress.

\section{Analysis and Findings}

The purpose of this study was to investigate teacher metacognition within the context of successful PLCs to gain a better understanding of how teachers describe their metacognition, what they describe as the catalysts to their metacognition, and how metacognition influences their work. This study yielded two findings. The first finding is that the PLC was an environment in which teacher metacognition could be nurtured. Although the PLC was chosen as a context for this study, it was not anticipated that the environment would nurture metacognition. This study revealed that, as members of PLCs, participants had the opportunity to reflect on and analyze their thoughts, and to different degrees, put or plan to put thoughts to action. The second finding is that the PLC leaders' metacognitive ability impacted the type of work that they led in the PLC. These will be discussed through a presentation of the data below.

\subsection{The Professional Learning Community as an Environment for Metacognition}

It was assumed that in order to know whether or not metacognition has taken place, it has to be seen or discussed (Georghiades, 2004). It was also assumed that the environment of a PLC, as described by Dufour et al. (1998), would create the opportunity for such metacognition. Both of these were found to be true, as all three participants we able to recognize and describe their metacognition. In addition, however, was that the PLC was not only an environment where metacognition could occur, but that it was also an environment where metacognitive thinking could be developed or nurtured. In his research on situated metacognition, Von Wright (1992) identified that metacognition occurs both a lower level and at a higher level, but metacognition is nurtured when higher level thinking occurs. In contrast to thinking at a lower level, where one engages in reflection on what one does, thinking at a higher level includes a reflection on how one reflects. Described as such, at a lower level, Lisa realized that because the basic structure of the PLC included setting a common goal, that members of the PLC could take advantage of common thinking that was bound to happen:

Because we're directed in what we're doing, each meeting has a strong focus. We don't have to backtrack and re-evaluate what that goal is...we were all going to the same place, and we were all using the same writing prompts, because we made them together and we were using the same assessment tools, and we were using the same language. We just talked about the same things.

Jacki appreciated that the PLC gave her the time and space to engage in deeper thinking:

Maybe the PLC, now that I'm sitting here thinking about it, maybe one of its purposes, besides improving learning, is to give us that time to kick the stuff around without feeling like we're getting anywhere. Because when else will I pick the time to sit around and think about this like we're doing right now?

Jacki added that discussions that took place in the PLC would not happen to the level or depth had the PLC not existed. She said that even though there "might be collegial collaboration between two people in a hallway or there might have been some sharing of resources", these occurrences would be occasional and irregular without the PLC.

The discussions in the PLC brought Jacki to a heightened awareness of the strategies that she used in her classroom. Thinking at a higher level, Jacki found that discussing the goals and the best strategies served as a reminder for her to ponder certain questions and follow certain plans as she taught. When recalling her thoughts following PLC meetings, she realized that the PLC impacted her day to day thinking: "It gives me something to stop and think about or be aware of during the day. It pops into my head, even as I'm teaching”. As a result, Jacki's opinion of the PLC changed as the year went on, from thinking that it was just another meeting to realizing that it affected her work. 
At a lower metacognitive level, Tracey recognized PLC meetings as a time where she could sort out her thoughts and reflect on the processes taking place in the classroom. She described that if, at a PLC meeting, someone was talking about their own classroom, it would cause her to engage in reflection what was happening in her classroom:

If someone is describing a strategy that doesn't work, you're thinking $O K$, what is this person doing that the strategy doesn't work. Or thinking, how can I do something to help this person or what is this person doing that they can change that might make it more successful...or if someone is talking about something successful that maybe isn't so successful in my classroom, then my thinking is I should use that or It doesn't work in my class are because of this.

At a higher metacognitive level, Tracey recognized that in order for people to reflect even at a lower level, they needed a certain environment of comfort and security for sharing, and she worked at ensuring that this environment was present in her PLC. Once the sharing began, members could examine their behaviors and figure out how to improve:

I think the purpose of saying what's not working is so that people will share what's working for them. Or if they're not doing what's working in their classroom they can at least share ways that they can go about making it successful.

Tracey added that the function of the PLC was not only to improve student learning, but that it was actually a structure that allowed for deeper thinking for herself and others. This deeper thinking was the key to improvement. She said that:

It helps you to think, and it helps you to think about the questions that people wonder. If someone has a strategy, for example, and you don't think it's going to work in your classroom, it helps you to think about all the roadblocks in the questions in between. 'Is this going to help student learning?' 'Will it be effective in my classroom?' 'What will work in the classroom of my size?' 'What can I do to make adaptations or modifications for special-needs or for regular students?' All those kinds of things are all questions that come off when you're in a PLC, because everyone's thinking about them all at different times.

Tracey's understanding of not only the benefit of the conversation but the cognitive path that she engaged in while that conversation was taking place was an asset to her professional development. She described this path:

If something's going wrong, I need to know how to fix it. In order to fix it, I need to know what the problem is. In order to understand what the problem is, I need to think about the situation. And when I get to a question to where I don't know the answer that's where I need my PLC. Because I need to voice what's not going on, and I need an answer to it.

Whether participants in this study realized that the thinking in the PLCs occurred at a low level or a higher level, each considered the PLC time as an opportunity to reflect on behaviors or to reflect on thinking, and that the PLC nurtured that thinking. This opportunity was one that was valued and that they believed led to improving practice.

\subsection{The PLC Leader's Metacognition as an Influence to the Learning of Others}

Each participant in this study varied in metacognitive ability, ranging from the ability to be reflective about their behavior to the ability to be reflective about their reflection. In all cases, each participant's metacognition influenced how they used their understanding to learn or to affect the learning of others.

Jacki described that she thought about her own thinking usually at the end of her work day. This reflection-on-action (Schon, 1983) allowed her to analyze her behavior and sort her thinking. Although she took advantage of a few pauses in the day for reflection-in-action, these moments were not as sustained as the reflection-on-action in which she engaged on the drive home. She noted that at the end of the day,

my mind jumps around from one student to another and who knows what sets it off, but it might be a specific subject or specific behavior or specific interaction. Probably with three or four different students during the day. I do some self-examination, asking myself ‘was I not patient enough with them' or 'did I try enough' whether it was behavior or academics.

Jacki applied the self-knowledge to the ways that she operated within the PLC. When the discussions in the PLC weren't as fruitful as they could be, she thought that people just needed time to think. She'd adjourn the meeting, with the thought that people would just need to think about issues and that at the next meeting, discussions would likely go better.

Lisa had a different understanding of her own learning processes, and, like Jacki, used this understanding when leading her PLC group. She understood that in order for her to accept a new idea, she had to see it in action rather than accept it at the outset. She had to see that it was 'doable'. As a result, she applied this knowledge of how she 
approached change to the others in the group. As a result, she spent less time talking about the new initiatives during PLC meetings, and more time in people's classrooms experimenting with new approaches, hoping that change would take hold. Because of her awareness of how she approached new ideas or tasks, Lisa made assumptions that the other teachers in her PLC would appreciate the same approach:

Because I had used the kits before I was excited about them, because I knew it was doable, and I had seen it work with my own class. And I thought: Knowing my own colleagues, they didn't want to reinvent the wheel and pull things from all over the place. This was something that was already created for grade 5-6-7-8. It was doable.

For Lisa, this meant creating opportunities to enter other teachers' classrooms. The challenge to her, however, was that some people resisted the approach. She said that, "some of them would wish that you would just go away and quit bringing this new stuff on. But I just felt that even if you get them to look at one or two new skills that you put in the program, it's a good thing".

Despite the resistance, Lisa stuck to applying her approach to learning because she felt it would bring about the greatest change: "Sometimes you have to push it on them and let them see the value". Lisa felt that she needed to guide them through it. She explained her thinking: "You've done this before and you can walk them through it and hold their hand".

To her, the end result, which was seeing teachers using the program, was worth the efforts: "I've gotten someone else on board." From Lisa's perspective, the program itself was the catalyst to teacher learning: "I think if the program had not been there to kind of be the catalyst, it would have been a difficult year." In terms of impacting their learning, Lisa felt integral to the process: "I feel a bit of relief, because I pushed the program, and now it kind of sold itself".

Like Jacki and Lisa, Tracey's metacognitive knowledge about how she learned had an impact on her PLC group as well. But more like Jacki and less like Lisa, Tracey valued dialogue as a means to engage her learning. She emphasized that listening, discussion, and cooperative teaching and learning were the major avenues for improving her own teaching, so she set that environment up for her PLC:

I think that having a voice is important. And how they think, or how they believe that we can reach our goal. Whatever the goal is. And then from that the discussion on how we're going to do it as a team is important. And being understanding for other people is important. And listening. It's important to be able to listen to people, and to support them through their roadblocks.

She also explained that the commitment by the other teachers was key in the learning that would take place:

Investing, I think is huge ... There are conversations when someone will be invested in and some when they won't be. Some days are better than others. I don't think there is $100 \%$ investment all of the time. That's just the way it goes.

Dissimilar to Jacki, Tracey believed that disagreements in the PLC catalyzed learning. Rather than stop the PLC in order to minimize the conflict, Tracey believed that disagreements enriched the learning:

We need to have disagreements because it causes the conversation. And it makes you think about what you're doing in the classroom and what strategies you're using and how you're teaching the strategies. It makes you think about how the students learned and are they learning from the strategies. It would be unrealistic to think that there would be everyone always agreeing or doing the same thing all the time.

Tracey tracked the path of her learning, stating that she didn't always believe in opening herself up to other teachers. Rather, she admitted to disliking the idea of discussions and cooperative teaching early in her career. She explained that when she first started teaching, she preferred to keep thoughts to herself because sharing made her vulnerable to criticism from others. She explained that it was only when she examined her own thoughts about why dialogue and teaching with other teachers made her uncomfortable that she realized that dialogue was beneficial.

Years ago I had a real problem working in cooperative groups sometimes. I was uncomfortable with the cooperative learning aspect of my classroom because I was giving up control. In the giving up control I thought people would think I was bad and what if the principal would walk by? I didn't want him to think certain things. But at the same time, if I would've talked to someone else from a different classroom, and we would've talked about it and I could've voiced that, I might have been able to understand that. So I guess this is what this is all about. It's about conversation, and it's about feeling OK with things.

Like Jacki and Lisa, Tracey was aware of her cognition, and this level of metacognition influenced how she led the group: "People come to a different understanding because they have the opportunity to talk about it." 
Because of Tracey's metacognition, influenced by her knowledge and experiences as a leader of her PLC, she created opportunities for other teachers to enter into examinations of their own thinking and their own practice. She was very aware of her motives. She said, "I wanted them to do it too", and added:

It's not to make everyone believe what someone's thinking. I think everyone has a right to their own opinion and their own beliefs. But I think the conversation has to come around those ideas....and as long as we're having a discussion about whether it works or not, that's the key part.

Tracey was aware of her own metacognition. She knew what influenced her learning, and she knew that if she created the conditions for this to occur for her peers, they might also be motivated to work toward the goals. Because of this, she led conversations and activities within her PLC that would provide other members the opportunity to undergo similar thought processes in the hope that they would be able to achieve the same learning that she did. She also realized that the learning opportunities that she had allowed her to be a stronger professional. As a result, she exerted effort into recreating those learning opportunities for others.

\section{Discussion}

The purpose of this study was to investigate teacher metacognition within the context of successful PLCs to gain a better understanding of how teachers describe their metacognition, what they describe as the catalysts to their metacognition, and how metacognition influences their work. The three participants in this study described their experiences as members of their PLCs, and each was able to describe the thinking behind their thinking, however, each appeared to be aware of this thinking to different degrees. Despite the differences, the PLCs provided the environments in which the participants could reflect upon their work or their thinking, as well as push that thinking further. Each participant also described different experiences that allowed them to learn, and, as a result, the understanding of these experiences influenced their work in terms of their own professional learning and the ways in which they influenced the learning of those in the PLC.

For this study, it was assumed that the PLC was an appropriate context within which to study teacher metacognition, due to the reflective and discursive nature of the PLC. This assumption, although not explicitly stated in the research question, was found to be correct. Not only were the participants (sourced through the PLC) metacognitive, but that the environment of the PLC assisted them in nurturing their metacognitive ability. Furthermore, the participants, who were also leaders of the PLC, used their understanding or awareness of their own metacognition to further the learning of others within the PLC structure.

Flavell (1979) stated that metacognition includes the monitoring and regulation of thinking, and that it also includes a relational component, implying what Zohar and Ben David (2009) identified as a "deeper than” (p. 177) notion to thinking. Reiterated, metacognition refers to thinking that is deeper than what would be considered teacher cognition. Parallel to the higher learning that is required of professional growth for today's teacher (Kramarski \& Michalsky, 2009), teacher metacognition is the conscious realization that there is deeper thinking that motivates or influences one to regulate one's own learning or the learning of others within an environment.

Teaching today requires that teachers are capable of teaching students to be metacognitive, thus they must be metacognitive themselves (Georghiades, 2004; Schraw \& Moshman, 1995). This “deeper than” learning was exhibited by each teacher in this study, captured through their descriptions of their understanding of when their learning took place. Both lower level metacognition and higher level metacognition were evident.

The PLC played an effective role in allowing participants to recognize their own metacognition, and in further developing metacognition. Theoretical literature supports this practical finding. In solving today's problems of teaching and learning, there are no pre-made solutions, rather knowledge must be created. Schon (1995) identified that such problem-solving requires reflection, discussion, dialogue, and an examination of beliefs. As Schon stated, this is known as the scholarship of teaching, where one doesn't rest on what one knows, but one begins with what one knows and extends and transforms it, with knowledge moving from the inside-out. In contrast to traditional institutional epistemology (where knowledge is transmitted from one person to another), scholarship epistemology refers to bringing together theory and practice, and constructing new knowledge as a result of working together. The facets of the PLC that catalyze scholarship epistemology include working in an environment of trust, having a common goal, creating an opportunity for reflection, becoming engaged in dialogue, and being accountable for results.

The second finding from this study was that each PLC leader used their understanding of their own metacognition to influence the learning of others. There was evidence to this from all three members.

Working from Flavell, Miller and Miller (1985), who described metacognitive knowledge and metacognitive monitoring, Zohar and David (2009) identified a further component of metacognition termed Meta-Strategic 
Knowledge (MSK). They theorized that MSK is a branch of metacognitive monitoring that includes knowledge of tasks and knowledge of strategies (p. 181). Although not attaching a finite distinction between metacognition and cognition, MSK contributes the understanding that metacognition is the "higher order agent who is overlooking and governing the cognitive system” (p. 184).

The work of Zohar and David (2009) identifies MSK as a critical component of metacognition in teaching and learning, where the thinker is not only able to reflect on their thinking for the purpose of solving problems, but is actually aware of the type of thinking strategies that are being used in certain environments. Zohar and David emphasized that although metacognition includes higher order thinking, MSK refers to the important awareness of the strategies leading to that thinking.

Schraw and Moshman (1995) identified this critical procedural knowledge as creating metacognitive theories. Creating metacognitive theories is a higher level of metacognition that moves knowledge from the tacit to the formal so that learning can not only occur, but it can also be systematized. Creating a formal metacognitive theory "allows the individual to make informed choices about self-regulatory behaviors" (p. 361). The teachers in this study identified, through the descriptions of their own metacognition, their meta-strategic knowledge, and through articulating it, their metacognitive theories of how they engaged their own learning. As leaders of their PLCs, they also described how they used their metacognitive knowledge to attempt to allow others to learn as well. Learning from theory and from the exploratory work in this study, a view of what formal metacognitive theories look like may be emerging.

\section{Conclusion and Implications}

The purpose of this study was to investigate teacher metacognition within the context of successful PLCs to gain a better understanding of how teachers describe their metacognition, what they describe as the catalysts to their metacognition, and how metacognition influences their work. This study revealed that the PLC was an environment in which teacher metacognition could be nurtured, and that the PLC leader's recognition of their own metacognition impacted the type of work that they led in the PLC, thus potentially impacting the learning of others. It was also discussed that through describing their own metacognition, these teachers were able, to different degrees, emerge with their own metacognitive theories, revealing initial understandings of how each teacher gains control over their learning and uses it to assist in the learning of others.

Through describing teacher thinking as members of a PLC, this study has provided an initial response to meta-strategic knowledge and formal metacognitive research, indicating a potential avenue for further study into what formal metacognitive theories look like and how they are created. There is an opportunity for furthering this research to discover if indeed formal theories can be pulled from such work, and how they can be applied.

Because the opportunity to learn how to be metacognitive is influenced by learning opportunities or environments to do so (Veenman, et al., 2006), the results of this study lead to the implication that the PLC is not only an effective structure for the promotion of teacher professional development (Kramarsky \& Michalsky, 2008), but that it may also encourage the development of higher order thinking and metacognition. If we are to break the theory practice divide, it is important that policy-makers and educational leaders invest the time and dollars necessary to make successful PLCs an experience for all teachers.

Lastly, this study implies that professional learning requires that teachers undergo a shift in understanding that learning does not move from the outside-in; rather than it must move inside-out (Georghiades, 2004). According to Calderhead, (2006), this is a significant shift, and there is a need to apply the findings from research about teacher metacognition to pre-service teacher and in-service teacher education so that there is increased emphasis on thinking over memorization, or metacognition over mastery of skills. If metacognition is going to find its way into classrooms, policy-makers and leaders must find the means to make it so (Georghiades, 2004).

\section{References}

Anderson, S. J. (2002). Organizational learning in schools: A cross-case study of teacher supervisors' beliefs, actions, and practices. University of Pennsylvania, Indiana.

Brown, A. L. (1987). Metacognition, executive control, self-regulation, and other more mysterious mechanisms. In F. E. W. R. H. Kluwe (Ed.), Metacognition, motivation, and understanding (pp. 65-116). Hillsdale, New Jersey: Lawrence Erlbaum Associates.

Calderhead, J. (2006). Reflective teaching and teacher education. Teacher Education: Professionalism, social justice, and teacher education, 5(1), 35. 
Creswell, J. W. (2007). Qualitative inquiry and research design: Choosing among five approaches. Thousand Oaks: Sage Publications Inc.

Downing, K., Kwong, T., Chan, S. W., Lam, T. F., \& Downing, W. K. (2009). Problem-based learning and the development of metacognition. Higher Education, 57(5), 609-621. http://dx.doi.org/10.1007/s10734-008-9165-x

DuFour, R. (2004). What Is a" Professional Learning Community"? Educational leadership, 61(8), 6-11. http://dx.doi.org/10.1080/11926422.2004.9673370

Dufour, R., \& Eaker, R. (1998). Professional learning communities at work: Best practices for enhancing student achievement. Bloomington, IN: National Education Service.

Dufour, R., Dufour, R., \& Eaker, R. (2005). Recurring themes of professional learning communities and the assumptions they challenge. In R. Dufour, R. Dufour \& R. Eaker (Eds.), On common ground: The power of professional learning communities (pp. 7-29). Bloomington, IN: Solution Tree.

Flavell, J. H. (1976). Metacognitive aspects of problem solving. In L. B. Resnick (Ed.), The nature of intelligence (pp. 231-236). Hillsdale, NJ: Erlbaum.

Flavell, J. H. (1979). Metacognition and cognitive monitoring: A new area of cognitive-developmental inquiry. American Psychologist, 34, 906-911. http://dx.doi.org/10.1037//0003-066X.34.10.906

Flavell, J. H., Miller, P. H., \& Miller, S. A. (1985). Cognitive development: Prentice-Hall Englewood Cliffs, NJ. doi:10.1177/058310248501700908

Georghiades, P. (2004). From the general to the situated: Three decades of metacognition. International Journal of Science Education, 26(3), 365-383. http://dx.doi.org/10.1080/0950069032000119401

Harskamp, E. G., \& Henry, D. (2009). Introduction to this special issue. Educational Research and Evaluation. (15,5), 429. http://dx.doi.org/10.1080/13803610903444469

Kluwe, R. (1987). Executive decisions and regulation of problem solving behavior. Metacognition, motivation, and understanding, 31-64.

Kramarski, B., \& Michalsky, T. (2009). Investigating preservice teachers' professional growth in self-regulated learning environments. Journal of educational psychology, 101(1), 161. http://dx.doi.org/10.1037/a0013101

Lave, J. (1988). Cognition in practice. Boston: Cambridge. http://dx.doi.org/10.1017/CBO9780511609268.001

Lieberman, A., \& Pointer Mace, D. (2008). Teacher learning: The key to educational reform. Journal of Teacher Education, 59(3), 226. http://dx.doi.org/10.1177/0022487108317020

Merriam, S. B. (1998). Qualitative research and case study applications in education. San Francisco: Jossey-Bass.

Mitchell, C., \& Sackney, L. (2000). Profound improvement: Building capacity for a learning community. Lisse, The Netherlands: Swets \& Zeitlinger.

Moustakas, C. (1994). Phenomenological research methods. Thousand Oaks: Sage Publications Inc.

Perfect, T. J., \& Schwartz, B. L. (2002). Applied Metacognition. New York: Cambridge University Press. http://dx.doi.org/10.1017/CBO9780511489976

Prytula, M., Makahonuk, C., Syrota, N., \& Pesenti, M. (2009). Successful Teacher Induction through Communities of Practice. Saskatoon, SK, Canada: Dr. Stirling McDowell Foundation for Research into Teaching.

Robson, S. (2006). Developing thinking and understanding in young children. New York: Routledge.

Schon, D. A. (1983). The reflective practitioner: How professionals think in action. New York: Basic Books.

Schon, D. A. (1995). The new scholarship requires a new epistemology. Change, 27(6), 1-9.

Schraw, G., \& Moshman, D. (1995a). Metacognitive theories. Educational psychology review, 7(4), 351-371. http://dx.doi.org/10.1007/BF02212307

Schunk, D. H. (2008). Metacognition, self-regulation, and self-regulated learning: Research recommendations. Educational psychology review, 20(4), 463-467. http://dx.doi.org/10.1007/s10648-008-9086-3

Sickle, M. V., \& Kubinec, W. (2003). Transforming teaching. Journal of College Science Teaching, 32(4), 258-263. 
Smith, K. J. (2005). Examining teachers' pedagogical decision making through collaborative metacognition. Claremont Graduate Univeristy and San Diego State University, Claremont, CA.

Veenman, M. V. J., Van Hout-Wolters, B. H. A. M., \& Afflerbach, P. (2006). Metacognition and learning: Conceptual and methodological considerations. Metacognition and Learning, 1(1), 3-14. http://dx.doi.org/10.1007/s11409-006-6893-0

Von Wright, J. (1992). Reflections on reflection. Learning and instruction, 2(1), 59-68. http://dx.doi.org/10.1016/0959-4752(92)90005-7

Webster-Wright, A. (2009). Reframing professional development through understanding authentic professional learning. Review of educational research, 79(2), 702. http://dx.doi.org/10.3102/0034654308330970

Wen, Y.-H. (2004). Development and validation of the thinking in teaching scale. University of Colorado, Greeley, CO. http://dx.doi.org/10.1117/12.571579

Zohar, A., \& Ben David, A. (2009). Paving a clear path in a thick forest: a conceptual analysis of a metacognitive component. Metacognition and Learning, 4(3), 177-195. http://dx.doi.org/10.1007/s11409-009-9044-6 